\title{
○ENTRE PENALISTAS E NEUROCIENTISTAS: REFLEXÕES SOBRE A INFLUÊNCIA DE ESTUDOS DA NEUROCIÊNCIA SOBRE O CONCEITO JURÍDICO-PENAL DE CULPABILIDADE
}

\author{
BETWEEN PENALISTS AND NEUROSCIENTISTS: \\ REFLECTIONS ON THE INFLUENCE OF NEUROSCIENCE STUDIES ON THE \\ LEGAL-CRIMINAL CONCEPT OF CULPABILITY
}

\begin{abstract}
João Pedro Gomes Dadda
Universidade do Vale do Rio dos Sinos - UNISINOS

Especialista em Direito Penal e Direito Processual Penal pela UNISINOS

Defensor Público do Estado do Rio Grande do Sul

Osório/Rio Grande do Sul/Brasil

jp_dadda@hotmail.com

(iD) André Olivier

Universidade do Vale do Rio dos Sinos - UNISINOS

Doutor em Filosofia pela UNISINOS

Professor Pesquisador do Programa de Pós-Graduação em Direito e Coordenador do Curso de Graduação em Direito da UNISINOS

São Leopoldo/Rio Grande do Sul/Brasil andreluiz@unisinos.br
\end{abstract}

\begin{abstract}
Resumo: O presente estudo aborda as influências da neurociência cognitiva no Direito Penal, mais precisamente no conceito de culpabilidade enquanto elemento do crime. A problemática reside no fato de que, enquanto a dogmática jurídico-penal pressupõe, para a caracterização da culpabilidade e, portanto, do crime, a existência de um sujeito livre, capaz de agir de forma que não a desviante, estudos neurocientíficos apontam o livre-arbítrio como mera ilusão. Diante disso, busca-se verificar em que medida as descobertas da neurociência acerca do livre-arbítrio exercem influência sobre a culpabilidade. Para tanto, aborda-se, de um lado, o entendimento de neurocientistas, que negam a existência do livre-arbítrio, e, de outro, o entendimento de penalistas, que rechaçam a ideia de um ser humano determinado por leis causais.
\end{abstract}

Palavras-chave: direito penal; culpabilidade; neurociência.

Abstract: The present study addresses the influences of cognitive neuroscience in criminal law, more precisely in the concept of culpability as an element of crime. The problem lies in the fact that, while criminal dogmatics presupposes, for the characterization of guilt and, therefore, crime, the existence of a free individual, capable of acting in a way that is not deviant, neuroscientific studies show free will as an illusion. In view of this, we seek to verify to what extent the discoveries of neuroscience about free will influence culpability. To do so, it addresses, on the one hand, the understanding of neuroscientists, who deny the existence of free 
DADDA, João Pedro Gomes; OLIVIER, André. Entre penalistas e neurocientistas: reflexões sobre a influência de estudos da neurociência sobre o conceito jurídico-penal de culpabilidade

will, and, on the other, the understanding of penalists, who reject the idea of a human being determined by causal laws.

Keywords: criminal law; culpability; neuroscience.

Para citar este artigo (ABNT NBR 6023:2018)

DADDA, João Pedro Gomes; OLIVIER, André. Entre penalistas e neurocientistas: reflexões sobre a influência de estudos da neurociência sobre o conceito jurídico-penal de culpabilidade. Revista Thesis Juris - RTJ, São Paulo, v. 10, n. 2, p. 253-279, jul./dez. 2021. http://doi.org/10.5585/rtj.v10i2.18147.

\section{Introdução}

Os avanços das ciências empíricas naturais exerceram - e continuam a exercer influência sobre outros ramos do conhecimento, entre os quais se encontra o Direito. Ocorre que, no tocante ao Direito Penal, tais avanços podem exercer uma influência determinante. Conforme progridem os estudos neurocientíficos, a discussão filosófica entre livre-arbítrio e determinismo ganha novos contornos, colocando em xeque institutos até então consolidados, sobretudo quando se discute a responsabilização pelo cometimento de um crime, que tem como pressuposto, em maior ou menor medida, a vontade livre e consciente do sujeito.

O presente estudo trata, pois, da influência das descobertas neurocientíficas no Direito Penal, especialmente no que se refere à possibilidade de subsistência do conceito de culpabilidade, enquanto elemento do crime, e de seu pressuposto da exigibilidade de conduta diversa. A divergência estabelecida na doutrina reside na controvérsia havida entre neurocientistas e penalistas: de um lado, estudos neurocientíficos apontam para o abandono da noção de sujeito livre, pois este seria determinado por leis causais, devendo-se alterar os pontos de partida da aplicação da pena; de outro, penalistas resistem e acreditam que tais descobertas não têm o condão de alterar os princípios e as bases da dogmática jurídico-penal, fundados no livre-arbítrio do indivíduo. É certo, todavia, que o Direito Penal não pode ficar alheio aos avanços da neurociência. Diante disso, surge a seguinte questão: em que medida as descobertas da neurociência cognitiva acerca do livre-arbítrio exercem influência sobre a culpabilidade enquanto elemento constitutivo do crime?

Com a finalidade de se encontrarem fundamentos para enfrentar o problema posto, temse como objetivo da presente pesquisa verificar em que medida as descobertas da neurociência cognitiva acerca do livre-arbítrio exercem influência sobre o conceito de culpabilidade enquanto elemento do crime. A conclusão que se pretende extrair ao final do artigo é a de que 
DADDA, João Pedro Gomes; OLIVIER, André. Entre penalistas e neurocientistas: reflexões sobre a influência de estudos da neurociência sobre o conceito jurídico-penal de culpabilidade

os conhecimentos neurocientíficos não têm o condão de reestruturar ou substituir o conceito de culpabilidade, especialmente por não estarem limitados por direitos e garantias fundamentais.

A metodologia empregada no presente estudo consiste na revisão bibliográfica de textos publicados em livros e artigos científicos, nacionais e estrangeiros, sobre o tema, tanto de autores que trabalham com as ciências naturais empíricas, notadamente a neurociência, doravante denominados simplesmente de neurocientistas, quanto de autores dedicados ao estudo da dogmática jurídico-penal, especialmente a culpabilidade enquanto pressuposto do crime, designados no decorrer do texto como penalistas.

\section{A neurociência e seus avanços}

Nos últimos anos, descobertas neurocientíficas sobre o funcionamento do cérebro e sobre os processos de tomada de decisão mostraram que os pontos de partida da responsabilidade penal estariam errados. Isso representa uma mudança radical na atual noção de responsabilidade e pode mudar para sempre o sistema de reação frente ao comportamento desviante (CANCIO MELIÁ, 2013). Rotineiramente, o Direito se volta às ciências empíricas naturais para tentar encontrar respostas às questões que surgem quando se precisa entender o comportamento humano e o funcionamento do cérebro. Hoje, o mais novo ramo dentro do grande bloco das ciências empíricas naturais que pode fornecer tais respostas é a neurociência cognitiva, que ganhou destaque a partir do advento de novos instrumentos utilizados em pesquisas psicológicas (GREENE; COHEN, 2004).

A título de conceituação, conforme relatório produzido pela Royal Society of London, neurociência é o "estudo empírico do cérebro e do sistema nervoso conectado, e a neurociência contemporânea busca explicar como o comportamento humano surge da atividade cerebral" (MACKINTOSH, 2011, p. 1, tradução nossa). Já a neurociência cognitiva, mais especificamente, pode ser conceituada como o estudo dos mecanismos biológicos que sustentam a cognição, com foco específico nos substratos neuronais dos processos mentais e suas manifestações comportamentais (ERICKSON, 2010).

Inegável, pois, que a neurociência pode ajudar - e vem ajudando - na compreensão do comportamento humano ao apresentar evidências sobre como e por que uma pessoa agiu de certa forma, o que impacta diretamente o sistema de justiça, que se ocupa, justamente, da regulamentação de comportamentos (JONES et al., 2013). Todavia, um grande perigo ao se

\footnotetext{
${ }^{1}$ Do original: "Neuroscience is the empirical study of the brain and connected nervous system, and contemporary neuroscience seeks to explain how human behaviour arises from brain activity".
} 
DADDA, João Pedro Gomes; OLIVIER, André. Entre penalistas e neurocientistas: reflexões sobre a influência de estudos da neurociência sobre o conceito jurídico-penal de culpabilidade

confrontar ciências naturais empíricas e ciências sociais, especialmente o Direito, é pensar que a biologia pode explicar tudo (ELLIOTT, 1997). Assim, oportuno adiantar que, diferentemente do que pretendem alguns autores, não há um gene pontual para o comportamento violento ou antissocial, e pessoas que cometeram crimes não serão magicamente identificadas por estudo de imagens do cérebro (MACKINTOSH, 2011).

Ainda assim, conforme aduz Erickson (2010), é impossível imaginar o campo da neurociência cognitiva sem se levar em consideração as diversas técnicas de imagem cerebral, tidas como as grandes responsáveis pelas recentes conclusões neurocientíficas, visto que aumentaram consideravelmente a capacidade de neurocientistas de investigar a estrutura e as funções do cérebro. Dentro do imenso bloco da neurociência, existem diversas técnicas de estudo e monitoramento do cérebro humano. Notadamente, nos últimos 20 anos houve um rápido desenvolvimento dessas técnicas, isto é, de tecnologias que permitem a medição de alguma função ou estrutura cerebral sem a necessidade de cirurgias, mediante a análise da atividade ou de estruturas das células do cérebro (REES, 2011).

Inicialmente, cumpre mencionar as técnicas de neuroimagem da eletroencefalografia (Electroencephalography - EEG) e da magnetoencefalografia (Magnetoencephalography MEG), capazes de identificar minúsculos campos elétricos ou magnéticos produzidos pela atividade cerebral na superfície do couro cabeludo. Ao medir a atividade elétrica cerebral diretamente, tais técnicas têm alta precisão temporal, ao mesmo tempo em que apresentam baixa resolução espacial (MACKINTOSH, 2011).

No que se refere às descobertas neurocientíficas que tais técnicas propiciaram, destacase o experimento conduzido em 1983 por Benjamin Libet, cientista pioneiro na investigação da consciência humana por meio de monitoramento da atividade cerebral com EEG. Referido autor desenvolveu estudo que transformou definitivamente a forma como o funcionamento do cérebro e a noção de livre-arbítrio são vistos. Essencialmente, o experimento consistiu em monitorar o cérebro de uma pessoa enquanto ela movia dedos de uma das mãos e, antes de realizar o movimento, informava ao pesquisador qual das mãos foi a escolhida. De acordo com os resultados obtidos, Libet constatou que os atos voluntários livres são precedidos por uma mudança elétrica específica no cérebro, chamada de potencial de prontidão (readiness potential ou RP), que começa 550 milissegundos antes da ação. Ocorre que a consciência da intenção de agir surge apenas 350 milissegundos após o RP, de modo que a atividade motora acontece 200 milissegundos após a tomada de consciência (LIBET, 1999). Nas palavras do autor: 
DADDA, João Pedro Gomes; OLIVIER, André. Entre penalistas e neurocientistas: reflexões sobre a influência de estudos da neurociência sobre o conceito jurídico-penal de culpabilidade

O processo volitivo é, portanto, iniciado inconscientemente. Mas uma atividade consciente ainda pode controlar o resultado; ela pode vetar o ato. O livre-arbítrio, assim, não é excluído. Essas descobertas colocam restrições em visões de como o livre-arbítrio deve operar; não se inicia um ato voluntário, mas se controla a execução do ato. As descobertas também afetam perspectivas sobre culpa e responsabilidade. ${ }^{2}$ (LIBET, 1999, p. 48, tradução nossa).

Significa, pois, que, em um primeiro momento, de forma inconsciente, o indivíduo determina sua intenção. Frações de segundo mais tarde, ele toma consciência dessa determinação; e, depois disso, passadas mais algumas frações de segundo, ele efetivamente realiza a conduta.

Desde o experimento de Libet, diversos outros estudos de mesma natureza (Libet-style experiments) sustentaram que as decisões antecedem a tomada de consciência das próprias decisões (ROSKIES; NAHMIAS, 2017). Assim, outras pesquisas realizadas na década de 1980 chegaram à mesma conclusão do referido autor: atos voluntários são iniciados inconscientemente no cérebro (FISCHBORN, 2016). Mais recentemente, a neurociência passou por outro enorme avanço devido ao advento de novos métodos de investigação por neuroimagem. Isso resultou na possibilidade de se conhecer ainda melhor o que se entende por natureza humana, não sendo exagero classificar-se esse fenômeno como uma verdadeira “revolução neurocientífica” (FEIJOO SÁNCHEZ, 2011, p. 2).

A técnica mais comumente utilizada para estudar a estrutura do cérebro humano e medir sua atividade é a ressonância magnética (Magnetic Resonance Imaging - MRI), método mediante o qual são produzidas imagens da estrutura, da anatomia do cérebro. A partir dessa, surgiu a ressonância magnética funcional (Functional Magnetic Resonance Imaging - fMRI), capaz de gerar imagens dinâmicas que refletem padrões de atividade cerebral (MACKINTOSH, 2011). À fMRI é dado o título de protagonista dessa revolução neurocientífica, eis que, como um escâner cerebral, produz imagens capazes de mostrar a atividade neuronal do indivíduo ao medir o fluxo de sangue em certas partes do cérebro (CANCIO MELIÁ, 2013). A partir disso, é possível inferir a natureza do processo cerebral e sua localização durante uma atividade desenvolvida pelo indivíduo (REES, 2011).

Confirmando os estudos levados a cabo por Libet com o uso de EEG, testes realizados com o uso de fMRI concluíram que há uma dissociação entre a atividade neuronal que levou à decisão de realizar uma conduta e o momento em que o indivíduo tomou consciência de sua

\footnotetext{
${ }^{2}$ Do original: "The volitional process is therefore initiated unconsciously. But the conscious function could still control the outcome; it can veto the act. Free will is therefore not excluded. These findings put constraints on views of how free will may operate; it would not initiate a voluntary act but it could control performance of the act. The findings also affect views of guilt and responsibility".
} 
DADDA, João Pedro Gomes; OLIVIER, André. Entre penalistas e neurocientistas: reflexões sobre a influência de estudos da neurociência sobre o conceito jurídico-penal de culpabilidade

intenção. Um desses testes consistiu em monitorar o cérebro de indivíduos enquanto pressionavam teclas livremente com uma das mãos, direta ou esquerda. Observou-se que a atividade cerebral que concluiu por realizar a conduta com uma das mãos antecedeu em mais de dez segundos o momento em que o indivíduo tomou consciência de que decidiu pressionar a tecla (SINGER, 2011).

Assim, verifica-se que, a partir de novas técnicas de investigação por neuroimagem, neurocientistas passaram a afirmar que nossas percepções, emoções, decisões, planos, pensamentos, argumentos e atribuições de valor são moldados por sequências de estados neuronais que estão causalmente ligados (SINGER, 2011), de modo que o comportamento humano decorre de uma interação complexa de mecanismos neuronais (CHORVAT; MCCABE, 2004).

Como sustenta Erickson (2010, p. 57, tradução nossa), as pessoas são "guiadas quase inteiramente por cascatas químicas determinadas e inconscientes que exercem controle irresistível sobre o pensamento e o comportamento de um agente" ${ }^{3}$. Além disso, as pesquisas mostraram que o processo de tomada de decisão não parte das estruturas neuronais conscientes, mas, sim, das inconscientes (CANCIO MELIÁ, 2013). Assim, se antes do ato consciente de vontade há um processo neuronal que o determina, não haveria espaço para o livre-arbítrio, tampouco para consciência intermitente (HASSEMER, 2013).

Portanto, ao se extrair como conclusão dos estudos neurocientíficos que as decisões decorrem de processos orgânicos do cérebro conforme as leis causais (FERRACIOLI, 2017), tem-se uma mudança de paradigma: troca-se uma concepção de livre-arbítrio, na qual há possibilidade de o indivíduo agir de modo diverso, por uma noção de determinismo, segundo o qual o mundo seria determinado pelas leis da física e pelo estado passado das coisas, havendo apenas uma maneira pela qual as coisas podem ocorrer (GREENE; COHEN, 2004).

Singer (2011, p. 42) expõe que neurocientistas entendem que todas as funções do cérebro são determinadas por sua estrutura e pelas conexões existentes entre os neurônios, o que é conhecido como a "arquitetura funcional do cérebro". Nessa perspectiva, todas as funções do cérebro seriam desempenhadas por redes de neurônios e unicamente determinadas pela arquitetura funcional dessas conexões, que define o fluxo de sinais e a estrutura dos complexos padrões de atividade que são a base das funções cerebrais (SINGER, 2011).

Diante da noção de que padrões de atividade cerebral inconsciente são responsáveis pelas condutas humanas, Greene e Cohen aduzem que, muitas vezes, a pergunta que surge é:

\footnotetext{
${ }^{3}$ Do original: "they are guided almost entirely by determined and unconscious chemical cascades which exert irresistible control over na agent's thinking and behavior".
} 
DADDA, João Pedro Gomes; OLIVIER, André. Entre penalistas e neurocientistas: reflexões sobre a influência de estudos da neurociência sobre o conceito jurídico-penal de culpabilidade

foi "ele" mesmo? Foi "ele" mesmo, o indivíduo, ou foram sua educação, seus genes ou outras circunstâncias? (GREENE; COHEN, 2004). Tais indagações surgem porque as pessoas tendem a sentir que há um agente dentro do cérebro, o qual é livre para, a qualquer tempo, tomar decisões que se sobrepõem às tomadas pelo maquinário neuronal determinista (SINGER, 2011).

Percebe-se, pois, que as evidências decorrentes dos avanços da neurociência que negam o livre-arbítrio e apontam à ideia de um universo determinado parecem contradizer algo importante na concepção de ação humana. Tais descobertas não são coincidentes com o que cada indivíduo considera sobre seus atos, pois as pessoas, em geral, acreditam que a maioria de suas ações são decididas livremente e sem predeterminações de qualquer ordem (MONIZ, 2015). Por essa razão, rotineira e erroneamente,

[...] nós dizemos "decidimos desse modo porque..." e então declinamos as razões das quais estamos conscientes. Entretanto, grande parte da atividade que realmente preparou e determinou o processo de decisão foge da memória consciente. ${ }^{4}$ (SINGER, 2011, p. 43, tradução nossa).

Diante do exposto, verifica-se que os estudos neurocientíficos, contrariando o senso comum, apontam para a ausência de liberdade de escolha na tomada de decisões, sendo todas as ações iniciadas por processos cerebrais inconscientes, os quais são determinados por leis causais. Em contrapartida, a dogmática jurídico-penal baseia-se na liberdade de ação e tem na culpabilidade o pressuposto para aplicação da pena (FERRACIOLI, 2017), como se verá a seguir.

\section{A resistência dos penalistas}

Resistir à responsabilização penal pautada em critérios que não guardam relação com o livre-arbítrio e com a possibilidade de agir de modo diverso do desviante é, para os penalistas, quase instintivo. Seja por intuição ${ }^{5}$, seja pelo narcisismo típico do ser humano ${ }^{6}$, autores

\footnotetext{
${ }^{4}$ Do original: "We say 'we have decided in this way because... 'and then we give the reasons that we are consciously aware of. However, much of the activity that actually prepared and determined the decision process escapes conscious recollection".

${ }^{5}$ Singer (2011) expõe que o ser humano intuitivamente crê na possibilidade de decidir livremente o que vai fazer e quais fatores levará em consideração quando do planejamento de ações futuras.

${ }^{6}$ Greene e Cohen (2004) apontam como causa da dificuldade de aceitação do determinismo o narcisismo típico do ser humano. Para os referidos cientistas, as indagações sobre o livre-arbítrio devem seguir o mesmo destino das três grandes crenças narcisistas da história da humanidade, desvendadas por Copérnico, Darwin e Freud, respectivamente: a de que Terra reside no centro do universo; a de que a espécie humana não descende de outras espécies; e a de que o comportamento humano é regido pelo consciente. Afirmam os autores que "cada uma dessas crenças foi substituída por um humilhante entendimento científico acerca do nosso lugar no universo físico, e não há razão para crer que será diferente com nosso entendimento sobre o livre-arbítrio" (GREENE; COHEN, 2004, p. 1781).
} 
DADDA, João Pedro Gomes; OLIVIER, André. Entre penalistas e neurocientistas: reflexões sobre a influência de estudos da neurociência sobre o conceito jurídico-penal de culpabilidade

dedicados ao estudo do Direito Penal resistem a concepções deterministas do indivíduo, muito em razão das profundas raízes que a liberdade de escolha tem na dogmática jurídico-penal.

Como refere Amilton Bueno de Carvalho (2013), a estrutura penal está fundada na ideia de culpa, no exercício da livre consciência, do livre-arbítrio, de uma vontade soberana. Portanto, os conhecimentos desenvolvidos pelos neurocientistas, acima vistos, caso sejam corretos e adequados, "retiram a base de uma boa parte de nossas suposições sobre o direito penal e seu mundo" (HASSEMER, 2013, p. 214). Disso decorre a controvérsia principal, que reside no fato de que a ampla maioria dos penalistas resiste e entende que as descobertas neurocientíficas não devem afetar os pilares essenciais do Direito Penal (CANCIO MELIÁ, 2013).

Portanto, outra hipótese que se estabelece é a de que, para o Direito, os avanços da neurociência não mudam nada. Para Ferrajoli (2002), a tese determinista, caso se generalize, pode parecer absurda, pois todas as infrações, incluídas as leves e as difusas, como avançar o sinal de trânsito ou a evasão fiscal, seriam indícios de enfermidade, causas hereditárias ou influência do ambiente. Já para Zaffaroni e Pierangeli (2013, p. 111), a ideia de um sujeito determinado representa a degradação da imagem humana, visto que, "caso se negue a possibilidade de escolha humana, nega-se com isso qualquer forma de responsabilidade. Quem não pode escolher não pode ser responsável por nada, em nenhum sentido”.

No mesmo sentido, como refere Busato (2017), parte da doutrina entende que, com a negação do livre-arbítrio, não somente a culpabilidade seria descartada, mas junto com ela a possibilidade de responsabilização por qualquer fato, pois tudo estaria absolutamente predeterminado. Por isso, para o autor, "se não por outras razões, essa postura há de ser rechaçada por seu radicalismo e, de consequência, porque não se sustentaria qualquer tese jurídica em face de sua admissibilidade" (BUSATO, 2017, p. 77).

A resistência dos penalistas justifica-se porque o conceito de culpabilidade, enquanto elemento do crime ${ }^{7}$, evoluiu historicamente até se alicerçar no livre-arbítrio. Oportuno, pois, identificarem-se as principais teorias que explicaram e explicam a culpabilidade.

A partir das contribuições de Karl Binding, a culpabilidade começou a ser desenvolvida pela dogmática penal alemã (FLORÊNCIO FILHO, 2017). Conforme pontua Tangerino (2014, p. 64), foi com Binding, em 1872, que se inaugurou "uma concepção de culpa dentro de uma perspectiva sistemática, vale dizer, como elemento integrante de uma teoria do ilícito penal".

\footnotetext{
${ }^{7}$ Há controvérsia doutrinária acerca dos desdobramentos das categorias que constituem o crime. Prevalece na doutrina brasileira o conceito analítico tripartido de crime, segundo o qual crime é um fato típico, antijurídico e culpável, ou seja, constituído pelos elementos da tipicidade, antijuridicidade e culpabilidade (SANTOS, 2010).
} 
DADDA, João Pedro Gomes; OLIVIER, André. Entre penalistas e neurocientistas: reflexões sobre a influência de estudos da neurociência sobre o conceito jurídico-penal de culpabilidade

Ainda no século 19, surge o primeiro conceito psicológico de culpabilidade. Segundo Dias (2007, p. 511), o tratamento da culpa em uma categoria autônoma resultou em uma “concepção positivista-naturalista do conceito de crime, em que a culpa abrangia tendencialmente a totalidade dos elementos subjectivos do delito segundo uma compreensão eminentemente psicológica". Assim, a partir de uma metodologia de abordagem própria das ciências naturais, a teoria causalista da ação, baseada no denominado "sistema Lizst-Beling", compreende a teoria psicológica da culpabilidade (FLORÊNCIO FILHO, 2017, p. 54).

Como ressalta Sant'Anna (2015, p. 41), o conceito psicológico da culpabilidade, desenhado por Lizst, é marcado pela mera existência de um liame psicológico entre o indivíduo e o fato; afinal, "não havia um fundamento material para se afirmar ou negar a culpabilidade, como também não era a concepção de livre-arbítrio que orientava a materialização do Direito Penal".

Tal conceito veio a ser superado diante dos defeitos que apresenta, destacando-se sua incapacidade de abranger a imprudência inconsciente, em que não há relação psicológica entre indivíduo e fato, bem como sua insuficiência em valorar situações de anormal motivação de vontade, atualmente definidas como hipóteses de inexigibilidade de conduta diversa (SANTOS, 2010). Em razão dos equívocos em que incorreu a teoria psicológica, Reinhard Frank, unanimemente reconhecido como o fundador da teoria psicológico-normativa da culpabilidade (SANT'ANNA, 2015), foi o primeiro a reconhecer que um nexo psíquico entre autor e resultado era insuficiente para a concepção de culpabilidade (FLORÊNCIO FILHO, 2017). Tem-se, assim, uma mudança de paradigma, pois rompe-se com a neutralidade axiológica própria do positivismo ao mesmo tempo em que se começam a reintroduzir valores no pensamento jurídico, de modo que o conceito psicológico, embora ainda necessário, não se revelava mais suficiente (SANT'ANNA, 2015).

Assim, com a introdução do componente normativo no conceito de culpabilidade, produziu-se o conceito psicológico-normativo de culpabilidade, dominante na primeira metade do século 20, sendo a culpabilidade definida como: a capacidade de culpabilidade; a relação psicológica concreta do autor com o fato, sob as formas de dolo ou imprudência; e a exigibilidade de comportamento diverso fundada na normalidade das circunstâncias do fato (SANTOS, 2010).

Todavia, o giro conceitual da teoria do delito deu-se com o finalismo de Hans Welzel, responsável por reestruturar os elementos contidos na tipicidade e na culpabilidade, com o deslocamento do dolo para a tipicidade, e a explicação da culpabilidade a partir da teoria normativa pura (FLORÊNCIO FILHO, 2017). Assim, na segunda metade do século 20, a teoria 
DADDA, João Pedro Gomes; OLIVIER, André. Entre penalistas e neurocientistas: reflexões sobre a influência de estudos da neurociência sobre o conceito jurídico-penal de culpabilidade

finalista e o conceito de injusto de Welzel resultaram na exclusão dos componentes psicológicos da culpabilidade, que restou reduzida a elementos normativos (SANTOS, 2010).

Como ensina Hans Welzel (2001, p. 91), “a doutrina da ação finalista situa o dolo [...] em seu lugar apropriado, como uma espécie da vontade final de ação, no tipo (subjetivo) dos delitos dolosos". Welzel vai além ao sustentar que "o conceito de culpabilidade, como tal, não compreende, ao contrário, elementos subjetivo-anímicos e conserva apenas o critério normativo da reprovabilidade, com base no qual se examina se a vontade de ação é culpável" (WELZEL, 2001, p. 92).

Claus Roxin (2003, p. 796, tradução nossa) menciona, ainda, que o conceito normativo de culpabilidade acaba por eliminar desta os elementos que constituem seu único conteúdo no conceito psicológico de culpabilidade, e traz os três elementos que passaram a constituí-la: "a imputabilidade, a possibilidade de conhecimento de antijuridicidade e a exigência de uma conduta conforme a norma" ${ }^{8}$, tendo este último requisito, que se orienta pela existência do livrearbítrio, como fundamento material da culpabilidade (SANT'ANNA, 2015).

Dessa forma, a resistência dos penalistas havida na dogmática jurídico-penal em aceitar o determinismo justifica-se porque, a partir do finalismo, a culpabilidade passou a pautar-se em uma concepção normativa pura, que "está fundada na possibilidade de o homem, de acordo com o seu livre-arbítrio, poder optar pelo caminho correto" (OLIVEIRA; CALLEGARI, 2017, p. 338). Passou-se a exigir que o sujeito, nas circunstâncias do fato, tivesse a possibilidade de realizar outra conduta, de acordo com o ordenamento jurídico. Desse modo, a conduta só seria reprovável quando o sujeito, podendo realizar comportamento diverso, realizasse comportamento proibido pelo ordenamento jurídico, conforme ensinam Oliveira e Callegari (2017).

Nesse contexto, como afirma Ferrajoli (2002, p. 399), a culpabilidade pode ser concebida:

[...] como um elemento normativo não do autor, mas do delito, do qual designa, mais do que uma conotação psicológica, uma modalidade deôntica e, além disso, alética: o dever de abster-se de realizá-lo com base na possibilidade material da sua omissão ou da sua comissão. Pode-se, se for preferível, denominar "livre-arbítrio" a esta alternativa.

Oportuno observar que, para o referido autor, o livre-arbítrio, enquanto pressuposto normativo da culpabilidade, corresponde ao atuar, ao querer, e não ao ser do agente. Afinal, “de uma pessoa pode-se dizer que tem a possibilidade, e por isso o dever, de atuar de forma diferente

\footnotetext{
${ }^{8}$ Do original: "la imputabilidad, la posibilidad de conocimiento de la antijuridicidad (hoy $\$ 17$ ) y la exigibilidad de una conducta conforme a la norma".
} 
DADDA, João Pedro Gomes; OLIVIER, André. Entre penalistas e neurocientistas: reflexões sobre a influência de estudos da neurociência sobre o conceito jurídico-penal de culpabilidade

da que atua, mas não de ser diferente de como é" (FERRAJOLI, 2002, p. 399-400). Ainda, conforme sustenta Welzel (2001, p. 93), a reprovabilidade da culpabilidade pressupõe que o autor tenha podido adotar uma resolução de vontade conforme a norma, e isso não no sentido abstrato de um homem qualquer no lugar do autor, mas no sentido concreto de que "esse homem, nessa situação, teria podido adotar uma resolução de vontade de acordo com a norma”.

Percebe-se, assim, que o

[...] conceito normativo de culpabilidade funda-se, necessariamente, na crença de que o indivíduo é possuidor de livre-arbítrio e de capacidade de autodeterminação, sendo estes os pressupostos sobre os quais o sujeito será valorado em sua culpa. (GORGA; MARCHIONI, 2015, p. 103).

Noutras palavras, o fundamento material da reprovação, enquanto possibilidade de atuar de outro modo, nada mais é do que uma expressão que contém a ideia de livre-arbítrio (BUSATO, 2017).

Daí surge a denominada crise da culpabilidade, que pode ser entendida como uma crítica ao livre-arbítrio, muitas vezes feita por adeptos ao determinismo: é impossível comprovar cientificamente que o agente, no caso concreto, poderia ter atuado de outro modo, ou seja, poderia ter obedecido o ordenamento jurídico (BUSATO, 2017). Portanto, a tese da liberdade da vontade do conceito de culpabilidade seria indemonstrável (SANTOS, 2010).

Nessa linha, informa Mello (2014) que o conceito de liberdade trazido por Welzel foi objeto de diversas críticas, especialmente no tocante à inviabilidade de mostrar empiricamente as possibilidades efetivas de o sujeito agir conforme a norma e à dificuldade de o juiz, em um processo concreto, aferir o poder agir de outro modo. Efetivamente, não há como retornar no tempo para se verificar se o delinquente realmente teria a possibilidade de agir de outra forma (PACHECO FILHO, 2009).

Dias (1995) sustenta que a pergunta sobre se um certo agente, em certa situação, poderia concretamente ter agido de forma diversa corre sério risco de se tornar destituída de sentido, enquanto se requeira que a resposta mantenha relação com a realidade concreta e também psicológica; isso porque a resposta, qualquer que seja, é absolutamente inverificável.

Por isso, Hassemer (2013, p. 223) classifica a possibilidade de verificação do poder agir de outro modo como o "autoengano do penalista". Vai além o referido autor:

Esse autoengano, com sua ousada alegação de que o juiz criminal poderia penetrar cognitivamente no espaço em que a liberdade do sentenciado de agir diversamente aflora, poderia, assim imagino, ter incitado um ou outro árido neurocientista a aproximar-se com sua afiada agulha de pesquisa do balão da retórica jurídico-penal da liberdade. 
DADDA, João Pedro Gomes; OLIVIER, André. Entre penalistas e neurocientistas: reflexões sobre a influência de estudos da neurociência sobre o conceito jurídico-penal de culpabilidade

Diante dos questionamentos acerca da indemonstrabilidade do livre-arbítrio, surgem diversas teses que, em termos gerais, substituem a culpabilidade por outro instituto jurídico, indicam um novo fundamental material para a culpabilidade (que não a possibilidade de agir de modo diverso) ou buscam atribuição de outro sentido à compreensão sobre liberdade (SANT'ANNA, 2015). Entre elas, destacam-se as teorias funcionalistas, as motivadoras e as sociais, as quais buscaram fundamentar, substituir ou suprimir a culpabilidade (PACHECO FILHO, 2009).

Entre as teorias que visam a superar a culpabilidade baseada na possibilidade de atuar de outro modo e, portanto, no livre-arbítrio, Sant'Anna (2015) menciona o funcionalismo sistêmico, de Gunther Jakobs, para quem a culpabilidade depende da verificação dos fundamentos motivadores da ação, com independência de suposição sobre a existência ou não de livre-arbítrio, bem como o funcionalismo teleológico, de Claus Roxin, que associa a culpabilidade à justificação social da pena e a condiciona à capacidade de controle do sujeito, um critério suscetível de demonstração empírica.

Todavia, os posicionamentos substitutivos ou reestruturadores da culpabilidade, em especial pela instrumentalização do ser humano individual em busca da ferrenha defesa social, nunca conseguiram fundar a culpabilidade sobre bases que não as decorrentes da liberdade humana (PACHECO FILHO, 2009). Em razão disso, não se vê opção para a recusa ao determinismo, visto que a "única coisa possível de afirmar é que a liberdade de vontade parece condição indispensável para a afirmação da própria existência do direito” (BUSATO, 2017, p. 79).

\section{Impactos das descobertas neurocientíficas no conceito de culpabilidade}

A capacidade de influência da neurociência sobre o Direito não pode ser ignorada ou menosprezada. Ainda que digam respeito a campos distintos do conhecimento, a neurociência, enquanto ciência empírica, e o Direito, especialmente o Direito Penal, como ciência social, estão obrigados a entenderem-se (CRESPO, 2014). O ponto de contato abordado no presente estudo, como visto, diz respeito aos estudos por neuroimagem que sustentam o determinismo do ser humano e, por isso, podem impactar o conceito de culpabilidade, fundado no livrearbítrio. Isso porque os sistemas jurídicos ocidentais assentam na suposição de que as pessoas são agentes de seu próprio comportamento e, assim, responsáveis por suas decisões e comportamentos (ERICKSON, 2010). Afinal, "só um direito penal baseado numa culpa que 
DADDA, João Pedro Gomes; OLIVIER, André. Entre penalistas e neurocientistas: reflexões sobre a influência de estudos da neurociência sobre o conceito jurídico-penal de culpabilidade

tenha como fundamento o livre-arbítrio pode sentir-se abalado com as recentes descobertas da neurociência" (MONIZ, 2015, p. 919).

Esse antigo problema, que envolve a alternativa entre determinismo e livre-arbítrio, tem penetrado a história inteira do pensamento filosófico ocidental, como refere Ferrajoli (2002). Para o autor, segundo a hipótese determinista, todo fenômeno, inclusive intenções e ações, é efeito necessário e, por isso, inevitável de causas absolutamente condicionantes, de tipo físico, psíquico, ambiental, econômico ou social. Por outro lado, segundo a hipótese do livre-arbítrio, a vontade humana é livre e incondicionada, tendo os seres racionais a faculdade de autodeterminar-se, pois são donos de suas ações.

Efetivamente, essa capacidade de livre autodeterminação "é, em verdade, por muitos admitida (com especial paixão, em frequência, pelos penalistas), por outros também rechaçada (comumente pelos cultores das ciências naturais)" (ROXIN, 2006, p. 146-147). Ocorre que, baseados em evidências empíricas e científicas naturais, os novos subsídios da neurociência apontam para um indivíduo determinado por leis causais e, assim, colocam em xeque o conceito jurídico-penal da culpabilidade tradicional, pautado na possibilidade de responsabilização concreta e individual pelo fato de o sujeito não ter agido conforme o ordenamento jurídico quando poderia tê-lo feito (FERRACIOLI, 2017).

Ainda, a fim de evitar equívocos acerca da dimensão do problema, Feijoo Sanchez (2011) adverte que os estudos da neurociência não negam o fato de que o ser humano pode tomar decisões; em vez disso, pregam que tais decisões não são livres, mas determinadas por circunstâncias que não podem ser conscientemente controladas. Ou seja, "não se trata tanto de se as pessoas fazem o que decidiram, mas sim de por que decidiram em determinado sentido" 9 (FEIJOO SANCHEZ, 2011, p. 6, tradução nossa).

Fato é que, com a adoção das premissas neurocientíficas como verdades condicionantes da estrutura jurídico-penal, tem-se, necessariamente, conforme apresenta Busato (2014), uma destas duas hipóteses: ou se abandonariam os mecanismos de controle jurídico-penal, uma vez que deslegitimados, pois apoiados na culpabilidade; ou se admitira a existência de um controle baseado em critérios exclusivamente clínicos.

A primeira hipótese é trabalhada por Singer, segundo o qual a evidência empírica mostra-se incompatível com a opinião de que uma pessoa, no momento de tomar uma decisão, poderia ter decidido agir de modo diverso. Todavia, essa suposição é considerada a base de nossos sistemas legais e a justificativa para se atribuir responsabilidade a uma pessoa.

\footnotetext{
${ }^{9}$ Do original: "No se trata tanto de si las personas hacen lo que han decidido, sino más bien de porqué han decidido en un determinado sentido".
} 
DADDA, João Pedro Gomes; OLIVIER, André. Entre penalistas e neurocientistas: reflexões sobre a influência de estudos da neurociência sobre o conceito jurídico-penal de culpabilidade

"Consequentemente, pode-se argumentar que, se essa premissa for falsa, as pessoas não são responsáveis por suas ações e, portanto, isentas de sanções" ${ }^{10}$ (SINGER, 2011, p. 45, tradução nossa).

Nesse sentido, Bigenwald e Chambon (2019) aduzem que a noção de determinismo apresentada pela neurociência trata as ações, ao reduzi-las a causas neurológicas e inconscientes, como meros eventos e não como ações intencionais, de modo a tornar ilusória a possibilidade de o indivíduo obter resultados diversos. Como consequência, "não seríamos responsáveis, a menos que alguma outra noção pudesse ser identificada para salvar a agência humana e, portanto, a própria responsabilidade"11 (BIGENWALD; CHAMBON, 2019, p. 3, tradução nossa).

Todavia, essa conclusão pode ser precipitada. Diferentemente do que sugerem muitos neurocientistas, estudos por neuroimagem que levam ao determinismo, a exemplo dos desenvolvidos por Benjamin Libet, podem não ser aplicáveis quando se fala na prática de condutas delituosas, de modo que as evidências neurocientíficas acerca da inexistência de livrearbítrio limitar-se-iam à prática de ações simples, como mover um dedo ou uma mão, não se aplicando a condutas mais complexas, como cometer um crime, caso em que restaria ao indivíduo a possibilidade de agir de forma diversa.

Nesse sentido, Moniz defende que o determinismo fruto dos estudos realizados por Libet refere-se a pequenos atos da vida cotidiana, os quais não exigem grande reflexão. Para a autora, no caso de atos subsumíveis a um tipo penal, há reflexão sobre a conduta, e os estudos por neuroimagem "ainda pouco ou nada nos disseram quanto à consciência ou não da prática de atos relevantes para o direito penal" (MONIZ, 2015, p. 919).

Corroborando esse entendimento, Sandra Oliveira e Silva (2019) sustenta que a anunciada revolução neurocientífica não abalou, como se temia, a estrutura fundamental do Direito Penal da culpa, especialmente porque decorreu de experimentos que dizem respeito a um âmbito limitado de ações simples e axiologicamente neutras, realizadas de forma automática, mecânica, sem a reflexão ou ponderação inerentes a uma decisão contra as normas morais e penais.

$\mathrm{Na}$ tentativa de comprovar empiricamente esse argumento e investigar se correta a generalização das conclusões deterministas a qualquer tipo de tomada de decisão, assim

\footnotetext{
${ }^{10}$ Do original: "Consequently, it could be argued that if this premise is false, persons are not responsible for their actions and therefore exempt from sanctions".

${ }^{11}$ Do original: "we would not be responsible, unless some other notion could be identified to salvage human agency and thus, responsibility itself".
} 
DADDA, João Pedro Gomes; OLIVIER, André. Entre penalistas e neurocientistas: reflexões sobre a influência de estudos da neurociência sobre o conceito jurídico-penal de culpabilidade

colocando à prova os estudos de Libet e os subsequentes que chegaram às mesmas conclusões, tem-se a pesquisa conduzida pelos neurocientistas Maoz et al. (2019). Tal pesquisa consistiu em monitorar o cérebro de indivíduos, com a utilização da técnica de neuroimagem EEG, durante a tomada de decisões na tarefa de doar mil dólares a organizações sem fins lucrativos, comparando-se as assim denominadas decisões arbitrárias e decisões deliberadas (MAOZ et al., 2019).

Os autores observaram que diversos estudos de monitoramento do cérebro que apontaram à falta de livre-arbítrio baseavam-se na realização de ações simples, tal como mover uma das mãos. Ocorre que decisões de como e qual mão mover são sempre irracionais, sem propósito e desprovidas de consequência, classificadas como decisões arbitrárias. Tais decisões, entretanto, contrastam com aquelas tomadas na vida real, que são fundamentadas, dotadas de propósito, sujeitas a consequências, denominadas de decisões deliberadas. Tal distinção se mostra importante, visto que as decisões deliberadas, e não as arbitrárias, é que estão no centro do debate filosófico sobre livre-arbítrio e responsabilidade (MAOZ et al., 2019).

Como resultado, Maoz et al. (2019) verificaram que mudanças elétricas específicas do cérebro não antecedem decisões deliberadas ou são ínfimas nesses casos. Isso porque as decisões deliberadas geralmente envolvem um processo de tomada de decisão mais consciente e demorado, enquanto as alterações elétricas do cérebro detectadas referem-se a processos inconscientes, próprios das decisões arbitrárias. Dessa forma, diferentes mecanismos neuronais são responsáveis por decisões arbitrárias e deliberadas, sendo inapropriada a generalização de estudos que argumentam que não há espaço para consciência na tomada de quaisquer decisões. Nas palavras dos autores:

\footnotetext{
Portanto, nossos resultados desafiam as afirmações baseadas no RP de Libet e da literatura subsequente contra o livre-arbítrio em decisões arbitrárias e, mais ainda, a generalização dessas afirmações para decisões deliberadas. As diferenças neuronais que encontramos entre decisões arbitrárias e deliberadas, assim como nosso modelo, colocam ainda mais ônus em qualquer estudo que tente tirar conclusões sobre o debate do livre-arbítrio a partir de decisões arbitrárias para demonstrar que essas conclusões se generalizam em decisões deliberadas. Isso motiva investigações futuras sobre outros precursores de ação, além do RP, usando EEG, fMRI ou outras técnicas. ${ }^{12}$ (MAOZ et al., 2019, p. 21, tradução nossa).
}

\footnotetext{
${ }^{12}$ Do original: "Hence, our results challenge RP-based claims of Libet and follow-up literature against free will in arbitrary decisions and much more so the generalization of these claims to deliberate decisions. The neural differences we found between arbitrary and deliberate decisions as well as our model further put the onus on any study trying to draw conclusions about the free-will debate from arbitrary decisions to demonstrate that these conclusions generalize to deliberate ones. This motivates future investigations into other precursors of action besides the RP using EEG, fMRI, or other techniques".
} 
DADDA, João Pedro Gomes; OLIVIER, André. Entre penalistas e neurocientistas: reflexões sobre a influência de estudos da neurociência sobre o conceito jurídico-penal de culpabilidade

Evidente que, no tocante à prática de crimes, está-se diante de decisões deliberadas, elaboradas, conscientes, relativas a condutas sujeitas a consequências, isto é, sujeitas a penas. Por isso, ao se trazer o estudo acima analisado para o Direito Penal e, mais especificamente, para o conceito de crime, resta evidente que a culpabilidade e seu pressuposto da exigibilidade de conduta diversa manter-se-iam íntegros, mesmo que considerados os avanços da neurociência. Além disso, sendo o Direito Penal uma disciplina essencialmente normativa que envolve fatores totalmente alheios ao que uma pessoa pode ou não realizar por impulsos cerebrais, jamais poder-se-ia ter a superação da ideia de liberdade no agir e sua relação com a teoria da pena adotada pelo sistema penal (BRITO, 2014).

Outrossim, a despeito de conclusões neurocientíficas deterministas, importante destacar que cabe à neurociência contribuir para a identificação da influência de antecedentes causais em condutas criminosas, mas cabe à lei estabelecer como tais antecedentes podem impactar a responsabilização penal (MACKINTOSH, 2011). Por essa razão, Hassemer (2013) defende que avanços da neurociência não têm influência alguma sobre a estrutura do Direito Penal. Para o autor, o ordenamento jurídico alemão - assim como o brasileiro - já traz previsão legal das causas excludentes da culpabilidade, que são "a porta pela qual os conhecimentos consolidados das ciências empíricas sobre a pessoa alcançam a determinação penal da culpabilidade" (HASSEMER, 2013, p. 224). Refere o autor que a lei não determina um procedimento positivo, mas sim um procedimento duplamente negativo, isto é, exige a ausência de alterações que fundamentariam a incapacidade de culpabilidade. Assim, o Direito Penal tem ouvidos abertos aos conhecimentos das ciências empíricas que podem levar a uma exclusão da responsabilidade (HASSEMER, 2013).

Por esse ângulo, Araújo (2014) afirma que, embora inadmissível a tese neurodeterminista, não se pode negar que a revolução neurocientífica pode contribuir de modo decisivo para o Direito Penal. Pesquisas da neurociência poderão identificar novas patologias ou facilitar a identificação das já conhecidas, oriundas de distúrbios nas células neuronais. E isso haverá de influir na identificação das hipóteses de inimputabilidade por doença mental e eventualmente na atenuação da responsabilidade penal, bem como auxiliará o Direito Penal no aperfeiçoamento do tratamento dentro das medidas de segurança (CASTRO; SOUZA, 2014).

Em sentido diverso, outra hipótese que se tem é a de que, caso válidos os estudos que apontam ao determinismo, o Direito Penal não está preparado para lidar com esse novo conhecimento. Isso porque o sistema penal não aborda essa nova possibilidade de se atribuir as condutas desviantes a ello (determinadas estruturas cerebrais) em vez de atribuí-las a él (ele, o 
DADDA, João Pedro Gomes; OLIVIER, André. Entre penalistas e neurocientistas: reflexões sobre a influência de estudos da neurociência sobre o conceito jurídico-penal de culpabilidade

sujeito), conforme pontua Cancio Meliá (2013) ao tratar da possível inimputabilidade e das disfunções cerebrais dos psicopatas.

Nessa linha, Greene e Cohen (2004, p. 1778-1779, tradução nossa) indagam: foi "ele" mesmo, ou foi seu cérebro? E concluem que "o que a maioria das pessoas não entende, apesar de filósofos naturalistas e cientistas terem dito isso por séculos, é que não há 'ele' independente dessas outras coisas"13. Assim, mesmo ao se adotar um determinismo radical e se concluir que o livre-arbítrio é uma ilusão, não seria correto afirmar que não há lugar legítimo para a responsabilidade (GREENE; COHEN, 2004).

Portanto, para os neurocientistas, ainda que novas tecnologias e estudos concluam que há uma relação causal entre determinado evento neuronal e determinada conduta, não se pode concluir que é inapropriado responsabilizar os indivíduos por seus atos (MACKINTOSH, 2011). Segundo esse entendimento, deve-se punir, mas justificando-se a imposição de uma pena não na retribuição, mas, sim, na prevenção.

Ao se aceitar que a consequência dos avanços da neurociência seria a queda de todo o edifício da responsabilidade jurídico-penal, que é baseado na liberdade de escolha, na censura e na culpabilidade, dar-se-ia lugar a um novo modelo de responsabilidade, baseado na perigosidade (ou periculosidade) e seu tratamento (CANCIO MELIÁ, 2013). Nessa perspectiva, Singer aduz que as evidências neurobiológicas não invalidam a visão de que uma pessoa é responsável pelo que ela faz, porque toda a autoria permanece com a pessoa que decide e age, o agente causal. Surgem, assim, indagações no tocante às medidas tomadas para prevenir comportamentos desviantes ou proteger a sociedade de danos: "elas devem ser modificadas diante da evidência de que o delinquente, no momento da ação, era incapaz de decidir de modo contrário?"14 (SINGER, 2011, p. 46, tradução nossa).

Greene e Cohen (2004) também sustentam que se pode privar a liberdade de indivíduos que cometeram crimes simplesmente porque a responsabilização e a detenção trariam efeitos benéficos à sociedade. Enquanto consequencialistas, os autores defendem que se deve atentar aos prováveis efeitos da punição, e não a saber se alguém é realmente inocente ou culpado em algum sentido que dependa do livre-arbítrio (GREENE; COHEN, 2004).

Nesse sentido, Erickson (2010) refere que, ao se admitir o comportamento criminoso como resultado de processos cerebrais, e não da escolha voluntária por agentes livres, o que

\footnotetext{
${ }^{13}$ Do original: "what most people do not understand, despite the fact that naturalistic philosophers and scientists have been saying it for cen-turies, is that there is no "him" independent of these other things".

${ }^{14}$ Do original: "Should they be modifi ed in view of the evidence that the delinquent, in the moment of his or her action was unable to decide otherwise?".
} 
DADDA, João Pedro Gomes; OLIVIER, André. Entre penalistas e neurocientistas: reflexões sobre a influência de estudos da neurociência sobre o conceito jurídico-penal de culpabilidade

importa não é se esses agentes sabiam que seu comportamento estava errado, mas se eles poderiam controlá-lo no futuro. Portanto, para o autor, ao se admitirem as influências dos estudos da neurociência sobre a lei penal, tem-se que “o que é necessário não é culpa e punição, mas intervenções terapêuticas formuladas pela ciência que podem controlar e mitigar danos futuros"15 (ERICKSON, 2010, p. 57, tradução nossa). Como destaca Mello (2014, p. 93):

[a] distinção entre um Direito Penal fundado na ideia de liberdade para outro fundado no neurodeterminismo estaria na substituição da culpabilidade pelas finalidades preventivas, e na substituição da pena por medidas de segurança.

Como consequência das constatações deterministas, Zaffaroni e Pierangeli (2013, p. 110-111) alertam para o risco de um direito penal pautado na periculosidade ao referirem que, “dentro desse pensamento, a culpabilidade será uma enteléquia, o reflexo de uma ilusão. [...] Esse será, assim, o direito penal de periculosidade, para o qual a pena terá como objeto (e também como único limite) a periculosidade”. Por isso, os referidos autores rechaçam de plano a tese determinista e defendem que, embora um indivíduo seja submetido a condicionamentos históricos de índole, nunca perde totalmente a sua capacidade de escolha, sua autonomia moral e, portanto, sua responsabilidade (ZAFFARONI; PIERANGELI, 2013).

Hassemer (2013, p. 212), ao advertir para os riscos de se incorrer nos mesmos erros do passado, trata as recentes descobertas da neurociência como o "canto das sereias", que não pode mais ser ignorado:

Tanto em termos de conteúdo, quanto estratégica e retoricamente, o canto me lembra [das] duas ondas que alcançaram o direito penal, e sobretudo a sua ciência, no passado recente: os antropometristas italianos, como Lombroso e Ferri, que, com a autoconfiança e o vigor das jovens ciências naturais exatas, miraram no coração do direito penal da culpabilidade, ao criar e levar adiante a figura do "criminoso nato"; e psicólogos e cientistas sociais como Arno Plack, que, na onda intelectual da crítica institucional e da fragmentação de sistemas dos anos 70, defendiam a abolição do direito penal e não tinham nada melhor a oferecer como alternativa do que um direito de medida de segurança aflitivo e decididamente menos amigável.

A tentativa de apropriação de conceitos neurocientíficos pelo Direito Penal pode parecer um déjà vu da Escola Positiva, quando, no passado, substituíram-se as irracionais togas negras pelos jalecos brancos da ciência, como pontua Cancio Meliá (2013), sendo certo que a adoção irrestrita de estudos próprios das ciências naturais empíricas que negam a existência do livrearbítrio e pretendem justificar a punição como mera forma de intervenção e proteção da sociedade remonta ao positivismo do século XIX. Para os positivistas, a pena não tinha nenhum significado ético ou jurídico, sendo apenas um recurso de intervenção, com a finalidade de

${ }^{15}$ Do original: "What is needed is not blame and punishment but therapeutic interventions formulated by science which can control and mitigate future harm". 
DADDA, João Pedro Gomes; OLIVIER, André. Entre penalistas e neurocientistas: reflexões sobre a influência de estudos da neurociência sobre o conceito jurídico-penal de culpabilidade

proteger a sociedade contra os criminosos. A pena, aliás, desaparece, dando lugar às medidas de segurança ou aos substitutivos penais (TANGERINO, 2014).

Tangerino relata que tal movimento teve seus filhos mais célebres na Itália, entre eles Cesare Lombroso, Enrico Ferri e Raffaele Garofalo, e foi marcado pelo sepultamento da culpa como decorrência direta do sepultamento do livre-arbítrio, restando apenas a denominada responsabilidade social, consequência do fato de se viver em sociedade e da necessidade de se assumir responsabilidade pelos atos praticados (TANGERINO, 2014).

De forma mais enfática, Busato (2014, p. 75) aduz, referindo-se a Lombroso, que:

[...] não é possível inferir nenhuma diferença, a respeito do objeto do seu conhecimento, das frases ditas pelos neurocientistas modernos, em sua pretensão de explicação da ausência de liberdade, e as explicações do médico militar italiano.

Alertando para os riscos de concepções neurocientíficas deterministas, Klaus Günther (2019) diz que pode ser uma surpresa que os neurocientistas, com sua proposta político-criminal de abolição do conceito de culpabilidade penal, tenham secundado a transformação do Direito Penal do cidadão em um Direito Penal do inimigo. Nas palavras do autor:

\footnotetext{
Desde distintas perspectivas, a revisão neurocientífica da concepção de um ser humano livre e a moderna política criminal - quase política de segurança - chegam à mesma conclusão: o delinquente não deve ser tratado como uma pessoa dotada de liberdade, discernimento e controle, mas como um conjunto de causas e efeitos sobre os quais o Estado, por sua vez, deve intervir causalmente, para obter determinados resultados. E é uma trágica ironia, cientificamente indecifrável, que os neurocientistas apresentem esse resultado de maneira humilde e o defendam em nome de um tratamento mais humano para os criminosos. (GÜNTHER, 2019, p. 249).
}

A adoção de um sistema baseado na prevenção pura e simples, fundada ou não na neurociência, tem consequências nefastas. Isso porque o discurso que visa à maximização da segurança da maioria não estabelece qualquer limite ou garantia do indivíduo em face da intervenção punitiva, ainda que fundado em critérios científicos. Nesse modelo, seriam admitidas medidas desproporcionais e violadoras da dignidade da pessoa humana (MELLO, 2014). Assim, o sonho de uma prevenção total pode facilmente tornar-se um pesadelo.

Um pesadelo voltado a apartar os fatores sociais e culturais que contribuem para fazer de nós aquilo que somos, ignorando o peso das desigualdades econômicas e políticas na determinação daquilo em que podemos nos tornar. (CARUNCHO; CABRAL, 2014, p. 153).

Portanto, num sistema garantista, a categoria da periculosidade não tem lugar, devendo a culpabilidade ser entendida como garantia no Direito Penal, garantia que se opõe às perversões positivistas dirigidas a conferir relevância penal autônoma à personalidade do 
DADDA, João Pedro Gomes; OLIVIER, André. Entre penalistas e neurocientistas: reflexões sobre a influência de estudos da neurociência sobre o conceito jurídico-penal de culpabilidade

acusado (FERRAJOLI, 2002). Conforme afirma Roxin (2006, p. 11), "no futuro, pode-se estender o campo de aplicação das medidas de segurança, mas uma substituição do direito penal por um direito de medidas de segurança não é possível e, em vários casos, sequer desejada".

Crespo (2014), em sentido semelhante, expõe que só a partir de uma consideração profundamente humanista pode ter cabimento no discurso penal qualquer avanço científico, incluído o pretendido pela neurociência. Assim, levar em consideração o que as ciências biológicas têm a dizer sobre o comportamento humano e sobre os critérios para imputar responsabilidade penal passa necessariamente pelo filtro do respeito à dignidade do ser humano. Para o referido autor, portanto, é possível aceitar a influência das descobertas da neurociência sobre o Direito Penal e a culpabilidade. Todavia:

[...] qualquer medida que se pudesse adotar como alternativa ao castigo tradicional [...] deveria respeitar sempre os mesmos limites e garantias materiais e processuais que amparam os sujeitos considerados culpáveis no marco do Estado de Direito. (CRESPO, 2014, p. 42).

Afinal, como observa Busato (2014), as garantias formuladas a partir do progressivo avanço das estruturas jurídicas, os princípios e os limites axiológicos decorrentes do reconhecimento da dignidade da pessoa humana não podem ceder diante de uma pretensão de tratamento baseada em um pretenso avanço científico. Nessa linha, entende Sebástian Borges de Albuquerque Mello (2014, p. 101) que:

\footnotetext{
Considerar o homem como culpável, numa concepção garantista e individualizadora, significa reconhecer, em certa medida, um grau de liberdade e de possibilidades de atuação alternativa do sujeito. Num Estado Democrático de Direito, a opção pelo indeterminismo parece inevitável, tendo em vista que a liberdade é concebida como dos mais decisivos direitos fundamentais no que se refere à dignidade humana. Não parece ser seriamente defensável um conceito de dignidade humana que prescinda do direito fundamental de liberdade.
}

Portanto, não se pode admitir o neurodeterminismo com a consequente extinção da culpabilidade, o que consagraria acentuado retrocesso na construção, ainda inacabada, de um Direito Penal liberal (ARAÚJO, 2014). O que se deve é fazer "melhor uso das descobertas da neurociência e neuroimagem, sem deixar que avanços, principalmente no campo dos direitos fundamentais, sejam maculados e submetidos a essas descobertas" (JUNCAL, 2017, p. 402).

Além disso, existe uma grande lacuna entre a pesquisa realizada por neurocientistas e as realidades cotidianas do sistema de justiça. Neurocientistas e profissionais do Direito realizam seu trabalho em diferentes ambientes, usando diferentes metodologias (MACKINTOSH, 2011). A natureza diferente do trabalho envolvido, do laboratório ao tribunal, 
DADDA, João Pedro Gomes; OLIVIER, André. Entre penalistas e neurocientistas: reflexões sobre a influência de estudos da neurociência sobre o conceito jurídico-penal de culpabilidade

leva, também, a diferenças culturais e de linguagem entre os dois grupos (MACKINTOSH, 2011).

Todavia, ao mesmo tempo em que o Direito Penal não pode ficar alheio aos avanços das ciências naturais, deve-se considerar que os conhecimentos neurocientíficos não se sobrepõem aos das ciências jurídicas, visto que as "ciências empíricas sobre a pessoa não têm a única palavra sobre a liberdade, assim como não têm a última. Essa única e última palavra, nomeadamente, não existe nesse mundo" (HASSEMER, 2013, p. 217).

Nesse sentido, Busato (2014) alude que esse discurso científico se ancora em uma pretendida verdade absoluta, a qual, sempre que espraia seus efeitos no tecido jurídico, é capaz de reeditar resultados funestos por demais conhecidos na história. "É justamente esse perfil de verdade que, em Direito, justificou historicamente atrocidades” (BUSATO, 2014, p. 58).

Disso decorre o "erro categorial" apontado por Hassemer (2013, p. 219). Para o autor, as diversas ciências têm concepções distintas de liberdade, e essas concepções não estão de acordo entre si. Pelo contrário, elas variam conforme o método e os instrumentos de pesquisa próprios de cada ciência; e ainda que existisse uma concepção geral de liberdade, não existe um poder de estipulação das ciências empíricas.

A título exemplificativo, apontam-se duas fragilidades nos estudos neurocientíficos sobre o tema, que dificultam a transplantação das conclusões neurocientíficas ao Direito Penal. A primeira delas tem relação com o fato de que a neurociência, enquanto ciência natural empírica, trabalha com estatísticas e probabilidades. Diante da diferença inerente aos indivíduos, a pesquisa neurocientífica é baseada em dados coletados a partir de grupos de indivíduos, o que permite alcançar-se uma representação média. Portanto, em um caso hipotético, ainda que haja uma diferença estatística abismal entre dois grupos estudados, não se pode afirmar que todos os membros de cada um dos grupos são diferentes (MACKINTOSH, 2011).

Por outro lado, o Direito trabalha com conclusões sobre um indivíduo específico, sobre um caso específico. Daí decore um problema quando se fala na aplicação de conhecimento baseado em estatísticas extraídas de estudos de grupo ao Direito e, mais especificamente, ao Direito Penal e Processual Penal. Ora, evidente que a existência de dados estatísticos baseados em estudos de grupo que, em um exemplo, indiquem que certo indivíduo possivelmente praticará um crime não permite que este seja tratado como criminoso presumido ou potencial.

A segunda fragilidade a ser mencionada reside na impossibilidade de demonstração da relação de causalidade havida entre determinada atividade ou estrutura cerebral e determinado comportamento criminoso com estudos por neuroimagem, não sendo possível afirmar que certa

Revista Thesis Juris - RTJ, São Paulo, v. 10, n. 2, p. 253-279, jul./dez. 2021 
DADDA, João Pedro Gomes; OLIVIER, André. Entre penalistas e neurocientistas: reflexões sobre a influência de estudos da neurociência sobre o conceito jurídico-penal de culpabilidade

alteração no cérebro, por exemplo, leva necessariamente a certo comportamento (MACKINTOSH, 2011).

Atualmente, resta claro que múltiplas estruturas cerebrais são responsáveis por múltiplos processos mentais e, assim, múltiplos comportamentos. Hoje, é evidente que as relações havidas entre uma estrutura cerebral e um processo mental não são vínculos diretos de "um para um". Diversamente, uma estrutura cerebral específica pode estar envolvida em muitos processos mentais; e um processo mental específico geralmente envolve várias áreas do cérebro. E esse mapeamento de processos mentais em áreas ou estruturas cerebrais de "muitos para muitos" torna difícil, se não impossível, inferir processos mentais específicos a partir da observação da atividade em uma área específica (MACKINTOSH, 2011, p. 6).

A par de tais advertências, pode-se sustentar que não existe conhecimento suficiente à fundamentação de decisão no sentido de que uma pessoa poderia na situação da ação ter agido de outro modo. Desmistificada a pretensão de certeza das ciências naturais empíricas, e verificado que os resultados dos estudos neurocientíficos não podem ser aplicados indistintamente a outras áreas do conhecimento, deve-se entender como, no mínimo, questionáveis as influências exercidas sobre o Direito Penal. Por isso, "esses resultados não podem ser lidos pela dogmática penal como vêm sendo divulgados pelos cientistas, isto é, não podem ser lidos como certeza científica, dada sua fragilidade experimental" (GUARAGNI; GUIMARÃES, 2014, p. 205).

Diante do exposto, tem-se que a neurociência está longe de causar uma revolução sobre o Direito Penal. Mais benéfico do que a pretensão de desconstruir as bases da dogmática jurídica seria estabelecer-se diálogo sutil entre a neurociência e o Direito, em uma abordagem na qual se reconheçam os obstáculos técnicos, interpretativos e legais que limitam a aplicação uniforme das ciências naturais (BIGENWALD; CHAMBON, 2019).

\section{Conclusão}

Pelo exposto, percebe-se que a controvérsia havida entre neurocientistas e penalistas está longe de acabar: enquanto os estudos da neurociência cognitiva baseados em técnicas de monitoramento do cérebro por neuroimagem avançam e apontam para o determinismo do ser humano, penalistas resistem e se apegam à ideia de que o indivíduo é dotado de livre-arbítrio e pode agir de forma que não a desviante, mantendo-se íntegro o conceito de culpabilidade.

A despeito de alguns avanços efetivamente havidos, os conhecimentos advindos das ciências naturais empíricas não podem ser superestimados. Além de apresentarem fragilidades 
DADDA, João Pedro Gomes; OLIVIER, André. Entre penalistas e neurocientistas: reflexões sobre a influência de estudos da neurociência sobre o conceito jurídico-penal de culpabilidade

experimentais, as técnicas de neuroimagem têm alto potencial quando limitadas ao uso nas áreas clínicas e de pesquisa e à análise de ações simples, de modo que não se mostram eficazes quando expostas a situações mais complexas, como o cometimento de um crime. Outrossim, os novos subsídios da neurociência não desconstroem o conceito de culpabilidade, mas, antes disso, podem contribuir para a elucidação de categorias já previstas na lei penal, tais como as excludentes da culpabilidade.

Ainda, não merece prosperar a conclusão de neurocientistas de que, a partir dos novos estudos empíricos, deve-se trocar a ideia de culpabilidade pela de periculosidade, pautando-se a pena na prevenção, com o uso indiscriminado de medidas de segurança, com a finalidade de tratamento, em verdadeiro revival da escola positiva; afinal, a culpabilidade deve ser entendida como verdadeira garantia, em oposição a um Direito Penal que se ocupe da personalidade do agente. Tem-se, assim, o que parece ser o principal fundamento da resistência dos penalistas: a neurociência, diferentemente da dogmática jurídico-penal, não está limitada por direitos e garantias fundamentais.

Ocorre que as divergências havidas entre distintos ramos do conhecimento não podem levar penalistas a ignorar por completo a evolução da neurociência e suas recentes descobertas acerca do funcionamento do cérebro e dos processos de tomada de decisão. Portanto, as diferenças devem ser superadas pelo constante diálogo, permitindo-se que os estudos das ciências naturais empíricas sejam recepcionados pelo Direito Penal e lidos à luz dos direitos e das garantais fundamentais, sendo, entretanto, justificável uma moderada resistência dos penalistas, a fim de se evoluir sem incorrer nas armadilhas do passado.

\section{Referências}

ARAÚJO, Fábio Roque da Silva. Culpabilidade, livre-arbítrio e neurodeterminismo: os reflexos jurídico-penais da revolução neurocientífica. Tese (Doutorado em Direito) Programa de Pós-Graduação em Direito, Universidade Federal da Bahia, Salvador, 2014.

BIGENWALD, Ariane; CHAMBON, Valerian. Criminal responsibility and neuroscience: no revolution yet. Frontiers in Psychology, v. 10, p. 1-19, jun. 2019. Disponível em: https:// www.frontiersin.org/articles/10.3389/fpsyg.2019.01406/full. Acesso em: 4 mar. 2020.

BRITO, Alexis Couto de. Neurociência e livre-arbítrio entre a dogmática penal e a política criminal. In: BUSATO, Paulo César (org.). Neurociência e direito penal. São Paulo: Atlas, 2014. p. 111-142.

BUSATO, Paulo César. Direito penal: parte geral. 3. ed. Rio de Janeiro: Atlas, 2017. 
DADDA, João Pedro Gomes; OLIVIER, André. Entre penalistas e neurocientistas: reflexões sobre a influência de estudos da neurociência sobre o conceito jurídico-penal de culpabilidade

BUSATO, Paulo César. Uma visão crítica das implicações dos estudos neurocientíficos em Direito Penal. In: BUSATO, Paulo César (org.). Neurociência e direito penal. São Paulo: Atlas, 2014. p. 49-82.

CANCIO MELIÁ, Manuel. Psicopatía y derecho penal: algunas consideraciones introductorias. In: CRESPO, Demetrio; CALATAYUD, Manuel Maroto. Neurociencias y derecho penal: nuevas perspectivas en el ámbito de la culpabilidad y tratamiento jurídicopenal de la peligrosidad. Madrid: Edisofer, 2013. p. 529-545.

CARUNCHO, Alexey Choi; CABRAL, Rodrigo Leite Ferreira. A neurociência e as consequências sancionatórias a partir de uma desconsideração da linguagem. In: BUSATO, Paulo César (org.). Neurociência e direito penal. São Paulo: Atlas, 2014. p. 143-164.

CARVALHO, Amilton Bueno de. Direito penal a marteladas: algo sobre Nietzsche e o direito. Rio de Janeiro: Lumen Juris, 2013.

CASTRO, José Roberto Wanderley de; SOUZA, Fernando Antônio C. Alves de. O retorno do discurso determinista no Direito Penal: uma introdução ao debate entre neurociências e dogmática penal. In: BUSATO, Paulo César (org.). Neurociência e direito penal. São Paulo: Atlas, 2014. p. 274-304.

CHORVAT, Terrence; MCCABE, Kevin. The Brain and the Law. Law and economics working paper series: forthcoming in Philosophical Transactions of the Royal Society of London. London: George Mason University School of Law, 2004. Disponível em: http:// www.law.gmu.edu/assets/files/publications/working_papers/04-33.pdf. Acesso em: 7 mar. 2020.

CRESPO, Eduardo Demetrio. "Compatibilismo humanista": uma proposta de conciliação entre neurociências e direito penal. In: BUSATO, Paulo César (org.). Neurociência e direito penal. São Paulo: Atlas, 2014. p. 17-48.

DIAS, Jorge de Figueiredo. Direito penal: parte geral. Tomo I: questões fundamentais: a doutrina geral do crime. 2. ed. Portugal: Coimbra Editora, 2007.

DIAS, Jorge de Figueiredo. Liberdade, culpa, direito penal. 3. ed. Coimbra: Coimbra, 1995.

ELLIOTT, Donald. Law and biology: the new synthesis? St. Louis University Law Journal, v. 41, n. 2, p. 595-624, 1997.

ERICKSON, Steven K. Blaming the brain. Minnesota Journal of Law, Science \& Technology, v. 11, n. 1, p. 27-77, 2010. Disponível em: https://papers.ssrn.com/sol3/papers.cfm?abstract_id=1472245. Acesso em: 8 mar. 2020.

FEIJOO SÁNCHEZ, Bernardo José. Derecho penal y neurociências: ¿una relación tormentosa? Revista para el análisis del Derecho, INDRET, Barcelona, n. 2, p. 1-57, abr. 2011. Disponível em: http://www.indret.com/pdf/806.pdf. Acesso em: 5 set. 2017.

FERRACIOLI, Jéssica. Notas sobre o neurodireito penal e a neurocriminologia. Revista Brasileira de Ciências Criminais, São Paulo, v. 132, a. 25, p. 17-37, jun. 2017. 
DADDA, João Pedro Gomes; OLIVIER, André. Entre penalistas e neurocientistas: reflexões sobre a influência de estudos da neurociência sobre o conceito jurídico-penal de culpabilidade

FERRAJOLI, Luigi. Direito e razão: teoria do garantismo penal. 3. ed. São Paulo: Revista dos Tribunais, 2002.

FLORÊNCIO FILHO, Marco Aurélio. Culpabilidade: crítica à presunção absoluta do conhecimento da lei penal. São Paulo: Saraiva, 2017.

FISCHBORN, Marcelo. Libet-style experiments, neuroscience, and libertarian free will. Philosophical Psychology, v. 29, n, 4, p. 494-502, 2016. DOI: https://doi.org/10.1080/09515089.2016.1141399. Acesso em: 6 mar. 2020.

GORGA, Maria Luiza; MARCHIONI, Guilherme Lobo. Liberdade da vontade, neurociência e culpabilidade. Revista Brasileira de Ciências Criminais, São Paulo, v. 114, a. 23, p. 99129, maio/jun. 2015.

GREENE, Joshua; COHEN, Jonathan. For the law, neuroscience changes nothing and everything. Philosophical Transactions of the Royal Society of London B, Special Issue on Law and the Brain, v. 359, p. 1775-1785, nov. 2004. Disponível em: https://www.ncbi.nlm.nih.gov/pmc/articles/PMC1693457/. Acesso em: 20 ago. 2017.

GUARAGNI, Fábio André; GUIMARÃES, Rodrigo Régnier Chemim. Neurociência, livrearbítrio e Direito Penal: precipitação científica e alternativas para sustentação da culpabilidade. In: BUSATO, Paulo César (org.). Neurociência e direito penal. São Paulo: Atlas, 2014. p. 165-214.

GÜNTHER, Klaus. Neurociências e o conceito de culpabilidade no direito penal. Tradução de Rodrigo Leite Ferreira Cabral, Paulo César Busato e Letícia da Lozzo. Revista Direitos Fundamentais e Democracia, Curitiba, v. 24, n. 3, p. 226-249, set./dez. 2019. Disponível em: https://revistaeletronicardfd.unibrasil.com.br/index.php/rdfd/article/view/1760/637. Acesso em: 15 mar. 2020.

HASSEMER, Winfried. Neurociências e culpabilidade em direito penal. Tradução de Helena Regina Lobo da Costa. Revista Brasileira de Ciências Criminais, São Paulo, v. 100, a. 21, p. 211-225, jan./fev. 2013.

JONES, Owen D. et al. Law and Neuroscience. The Journal of Neuroscience, v. 33, n. 45, p. 17624-17630, nov. 2013. Disponível em: https://www.jneurosci.org/content/33/45/17624. Acesso em: 7 mar. 2020.

JUNCAL, Regina Geni Amorim. A medida de segurança como a pior opção: por que os neurocientistas não devem dizer sobre como punir? Revista Brasileira de Ciências Criminais, São Paulo, v. 130, a. 25, p. 399-426, abr. 2017.

LIBET, Benjamin. Do we have free will? In: LIBET, Benjamin; FREEMAN, Anthony; SYTHERLAND, Keith (ed.). The Volitional Brain: Towards a neuroscience of free will. Thorverten: Imprint Academic, 1999. p. 47-57.

MACKINTOSH, Nicholas (coord.). Brain waves module 4: neuroscience and the law. Londres: The Royal Society, 2011. Disponível em: https://royalsociety.org/ /media/Royal_ Society_Content/policy/projects/brain-waves/Brain-Waves-4.pdf. Acesso em: 11 fev. 2020. 
DADDA, João Pedro Gomes; OLIVIER, André. Entre penalistas e neurocientistas: reflexões sobre a influência de estudos da neurociência sobre o conceito jurídico-penal de culpabilidade

MAOZ, Uri et al. Neural precursors of decisions that matter: an ERP study of deliberate and arbitrary choice. eLife Sciences Publications, Cambridge, p. 1-32, out. 2019. Disponível em: https://elifesciences.org/articles/39787. Acesso em: 18 fev. 2020.

MELLO, Sebástian Borges de Albuquerque. Culpabilidade e neurociências: entre problemas reais e imaginários. In: BUSATO, Paulo César (org.). Neurociência e direito penal. São Paulo: Atlas, 2014. p. 83-110.

MONIZ, Helena. Neurociências e direito penal: novos e velhos problemas. Revista Jurídica luso-Brasileira, Lisboa, n. 2, a. 1, p. 911-928, 2015. Disponível em:

https://www.cidp.pt/revistas/rjlb/2015/2/2015_02_0911_0928.pdf. Acesso em: 29 fev. 2020.

OLIVEIRA, Eugênio Pacceli de; CALLEGARI, André. Manual de direito penal: parte geral. 3. ed. São Paulo: Atlas, 2017.

PACHECO FILHO, Vilmar Velho. A crise da culpabilidade. Porto Alegre: Verbo Jurídico, 2009.

REES, Geraint Rees. The scope and limits of neuroimaging. In: BLAKEMORE, Colin (coord.). Brain waves module 1: neuroscience, society and policy. Londres: The Royal Society, 2011.p. 7-17. Disponível em: https://royalsociety.org/-/media/Royal_Society_ Content/policy/publications/2011/4294974932.pdf. Acesso em: 18 fev. 2020.

ROSKIES, Adina; NAHMIAS, Eddy. "Local determination", even if we could find it, does not challenge free will: commentary on Marcelo Fischborn. Philosophical Psychology, v. 30, n, 1-2, p. 185-197, 2017. DOI: https://doi.org/10.1080/09515089.2016.1248286. Acesso em: 6 mar. 2020.

ROXIN, Claus. Derecho penal: parte general. Madrid: Civitas, 2003.

ROXIN, Claus. Estudos de direito penal. Tradução de Luís Greco. Rio de Janeiro: Renovar, 2006.

SANT'ANNA, Marina de Cerqueira. Neurociências e culpabilidade. Florianópolis: Empório do Direito, 2015.

SANTOS, Juarez Cirino dos. Direito penal: parte geral. 4. ed. Florianópolis: Conceito Editorial, 2010.

SILVA, Sandra Oliveira e. It's all in your head? - a utilização probatória de métodos neurocientíficos no processo penal. Revista Eletrônica de Direito Processual, Rio de Janeiro, v. 20, n. 1, a. 13, p. 477-512, jan./abr. 2019. Disponível em: https://www.epublicacoes.uerj.br/index.php/redp/article/view/42215/29262. Acesso em: 15 mar. 2020.

SINGER, Wolf. A determinist view of brain, mind and consciousness. In: BLAKEMORE, Colin (coord.). Brain waves module 1: neuroscience, society and policy. Londres: The Royal Society, p. 41-78, 2011. Disponível em: https://royalsociety.org/-/media/Royal_Society_ Content/policy/publications/2011/4294974932.pdf. Acesso em: 18 fev. 2020.

TANGERINO, Davi de Paiva Costa. Culpabilidade. 2. ed. São Paulo: Saraiva, 2014. 
DADDA, João Pedro Gomes; OLIVIER, André. Entre penalistas e neurocientistas: reflexões sobre a influência de estudos da neurociência sobre o conceito jurídico-penal de culpabilidade

WELZEL, Hans. O novo sistema jurídico-penal: uma introdução à doutrina da ação finalista. São Paulo: Revista dos Tribunais, 2001.

ZAFFARONI, Eugenio Raúl; PIERANGELI; José Henrique. Manual de direito penal brasileiro: parte geral. 10. ed. São Paulo: Revista dos Tribunais, 2013. 